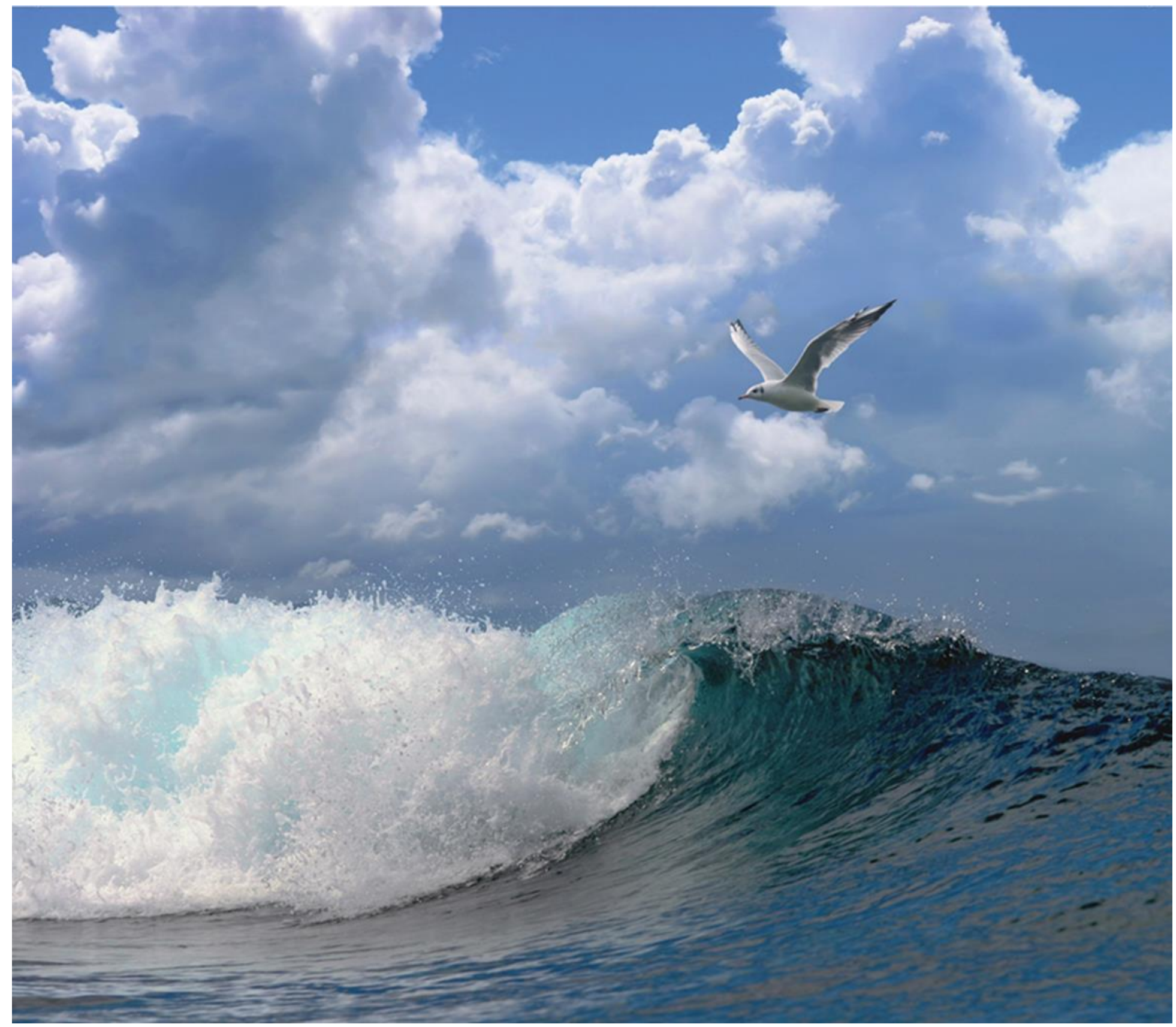

\title{
Bestandsopname van mosselen op mosselkweekpercelen in de Waddenzee in december 2019
}




\section{Bestandsopname van mosselen op mosselkweekpercelen in de Waddenzee in december 2019}

Auteur(s): Jacob J. Capelle \& Marnix R. van Stralen ${ }^{1}$

${ }^{1}$ Bureau Marinx, Scharendijke

Wageningen Marine Research

Yerseke, februari 2020

VERTROUWELIJK Nee

Wageningen Marine Research rapport C017/20 
Keywords: mosselbestand, mosselkweek, Waddenzee

Opdrachtgever: Ministerie van LNV en PO Mosselcultuur

Dit rapport is gratis te downloaden van https://doi.org/10.18174/515254

Wageningen Marine Research verstrekt geen gedrukte exemplaren van rapporten.

Wageningen Marine Research is ISO 9001:2015 gecertificeerd.

(c) Wageningen Marine Research

Wageningen Marine Research, instituut binnen de rechtspersoon Stichting Wageningen Research, hierbij vertegenwoordigd door Dr. M.C.Th. Scholten, Algemeen directeur

KvK nr. 09098104,

WMR BTW nr. NL 8113.83.696.B16.

Code BIC/SWIFT address: RABONL2U

IBAN code: NL 73 RABO 0373599285
Wageningen Marine Research aanvaardt geen aansprakelijkheid voor gevolgschade, noch voor schade welke voortvloeit uit toepassingen van de resultaten van werkzaamheden of andere gegevens verkregen van Wageningen Marine Research. Opdrachtgever vrijwaart Wageningen Marine Research van aanspraken van derden in verband met deze toepassing.

Alle rechten voorbehouden. Niets uit deze uitgave mag weergegeven en/of gepubliceerd worden, gefotokopieerd of op enige andere manier gebruikt worden zonder schriftelijke toestemming van de uitgever of auteur. 


\section{Inhoud}

Samenvatting

$1 \quad$ Inleiding

2 Werkwijze $\quad 6$

$\begin{array}{lll}2.1 & \text { Methode } & 6\end{array}$

2.2 Berekeningen 6

$\begin{array}{llr}3 & \text { Resultaten } & \mathbf{8}\end{array}$

4 Conclusie $r$

$5 \quad$ Literatuur $r$

$\begin{array}{lr}\text { Verantwoording } & 13\end{array}$

$\begin{array}{lr}\text { Bijlage } 1 \text { Monstergrid } & 14\end{array}$

$\begin{array}{lr}\text { Bijlage } 2 \text { Protocol monstername } & 17\end{array}$

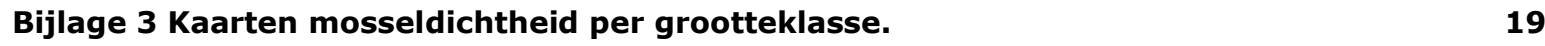

$\begin{array}{lr}\text { Bijlage } 4 \text { Bestand per kombergingsgebied } & 25\end{array}$ 


\section{Samenvatting}

Een van de uitgangspunten bij de mosselzaadvisserij is dat de omvang van het mosselbestand in de Waddenzee en daarmee het voedselaanbod voor vogels niet minder is dan in een situatie waar niet wordt gekweekt en gevist. Dat betekent dat in het najaar een zekere hoeveelheid mosselen op de kweekpercelen in de Waddenzee aanwezig dient te zijn. In 2019 (peildatum 1 december) is deze hoeveelheid vastgesteld op 31,8 miljoen $\mathrm{kg}$ netto versgewicht. Na de voorjaarsvisserij wordt met een bestandsopname een schatting gemaakt van het bestand op de kweekpercelen (de zogenaamde 'starthoeveelheid') en wordt vervolgens bijgehouden hoeveel mosselen afgevoerd worden en hoeveel mosselen erbij komen. Een tweede bestandsopname is bedoeld om te kunnen valideren of de eerder genoemde hoeveelheid mosselen aan het begin van de winter inderdaad op de percelen aanwezig is. Voorliggende rapportage betreft de bestandsopname van mosselen op percelen in de Waddenzee in december 2019, om te valideren of het bestand van 31,8 miljoen $\mathrm{kg}$ op 1 december 2019 op de percelen aanwezig was. Hiertoe zijn in de Waddenzee alle kweekpercelen of delen van kweekpercelen waar mosselen verwacht worden eind november en begin december 2019 bemonsterd. Het totale bestand op de percelen in december 2019 is hiermee geschat op 89,7 miljoen kg versgewicht. Op basis van deze schatting kan geconcludeerd worden dat de benodigde minimale hoeveelheid mosselen op 1 december 2019 ruimschoots op de percelen aanwezig was. 


\section{$1 \quad$ Inleiding}

Eén van de uitgangspunten voor de mosselzaadvisserij is dat het geheel van Vissen, Kweek en Afvoer van mosselen naar Zeeland ('VKA') niet leidt tot minder mosselen in de Waddenzee en daarmee tot minder voedsel voor overwinterende vogels dan in een situatie waarin niet zou worden gekweekt en gevist. De achtergronden hiervan zijn na te lezen in de passende beoordeling voor de mosselzaadvisserij Waddenzee (van Stralen 2018) en de NB-wet vergunning die voor de periode 2018-2020 door het ministerie van LNV voor deze visserij is verleend (LNV 2018).

Dit uitgangspunt betekent dat er in het najaar een zekere minimale hoeveelheid mosselen op de percelen aanwezig moet zijn, om als voedsel voor overwinterende vogels beschikbaar te zijn. Om dat te borgen wordt na de voorjaarsvisserij met een bestandsopname een schatting gemaakt van het bestand op de kweekpercelen (de zogenaamde 'starthoeveelheid'). Vervolgens wordt bijgehouden hoeveel mosselen naar Zeeland worden afgevoerd en hoeveel mosselen erbij komen uit MZI's, visserij en andere bronnen (bijvoorbeeld 'Zuid-Noord' transporten, d.w.z. transporten van mosselen uit Zeeland naar de Waddenzee).

Als onderdeel van de vergunningverlening voor de mosselzaadvisserij in het voorjaar van 2019 is berekend dat in het najaar van 2019 (ijkmoment 1 december) een bestand van minimaal 31,8 miljoen kg netto op kweekpercelen in de Waddenzee aanwezig dient te zijn (van Stralen 2019).

Het mosselbestand op de percelen na de voorjaarsvisserij van 2019 is geïnventariseerd in juni 2019. Dit resulteerde in een schatting van het mosselbestand van 94,1 miljoen kg netto versgewicht. De tweede bestandsopname in december 2019, beschreven in voorliggend rapport, is bedoeld om te kunnen valideren of de eerder genoemde minimale hoeveelheid mosselen van 31,8 miljoen kg netto versgewicht aan het begin van de winter, inderdaad op de percelen aanwezig was. 


\section{Werkwijze}

\section{$2.1 \quad$ Methode}

Voor de bestandsopname zijn bemonsteringsstations (hierna: stations) in een regelmatig grid over alle kweekpercelen gelegd. De stations liggen in noordelijke en oostelijke richting 0,2 bij 0,2 nautische minuten uit elkaar, dit komt overeen met een gridceloppervlak van 8,26 ha. Daarbij zijn (delen van) kweekpercelen waarvan bekend is dat zij niet in het gebruik zijn, bijvoorbeeld omdat zij droogvallen of het er te hard stroomt niet in het monsterprogramma opgenomen. In geval dat daar twijfel over was zijn deze wel in het programma opgenomen. Voor de verder achtergronden bij het opstellen van het monstergrid wordt verwezen naar Van Stralen (2013)

Om reden van efficiëntie is besloten om binnen het areaal dat wel wordt gebruikt voor mosselkweek en waar dus wordt gemonsterd onderscheid te maken tussen de meer en minder intensief benutte gedeelten. Monsterpunten waarvan uit de najaarsbemonstering in het verleden bleek dat deze minder intensief gebruikt zijn (0-33\% van de gevallen bezaaid), zijn hierbij ook minder intensief bemonsterd. Van deze stations zijn drie gridcellen tot een gridcel van 24,78 ha samengevoegd. Dit betekend dat over de percelen die in het verleden intensief gebruikt zijn een fijn monstergrid gelegd is, terwijl over percelen die minder intensief gebruikt zijn een grof monstergrid gelegd is (kaarten in Bijlage 1). Een evaluatie van het gebruik van dit grove en fijne grid is beschreven in Capelle en van Stralen (2019).

Er zijn in de periode van 25 november tot en met 15 december 2019325 stations bemonsterd, waarvan 214 stations volgens het fijne monstergrid en 111 stations volgens het grove monstergrid bemonsterd zijn. De bemonstering is uitgevoerd door buitendienst medewerkers van de Waddenunit van het Ministerie van LNV vanaf de Rijksvaartuigen "Asterias" en "Phoca". Het onderzoek is begeleid en gerapporteerd door Wageningen Marine Research, met als opdrachtgevers de PO Mosselcultuur en het ministerie van LNV. Per station zijn 5 happen genomen met een Van Veen bodemhapper wat resulteert in een bemonsterd oppervlak van $0.276 \mathrm{~m}^{2}$ per station. Uit deze happen zijn alle mosselen verzameld.

De mossel monsters zijn vervolgens verwerkt per station, protocol hiervoor is bijgevoegd in Bijlage 2. Per dag zijn alle verwerkte monsters van alle stations die op die dag bezocht zijn bijeengevoegd. Stations met vooral mosselzaad als vangst zijn daarbij apart gehouden van stations met voornamelijk halfwas en/of consumptie maatse mosselen. Dit levert per dag dus twee verzamelmonsters op. Aan het eind van de dag is van elk daarvan het volume bepaald (in liters) en is een deelmonster genomen van 6 liter uit het deel met voornamelijk halfwas en/of consumptiemaatse mosselen en 3.5 liter uit het deel met vooral mosselzaad. Deze metingen zijn aan het eind van elk dag dat er monters verzameld zijn uitgevoerd, zodat de monsters bij het doormeten niet ouder waren dan een dag en dus nog vers waren. De handleiding voor de verwerking van deze monsters is ook bijgevoegd in Bijlage 2.

Bij de zaadvisserij maar ook bij het verzaaien van bijvoorbeeld halfwasmosselen naar Zeeland wordt gerekend in bruto hoeveelheden (mosselen inclusies alle bijvangst zoals lege schelpen, zeewier en pokken). Er zijn daarom ook bruto bestandsschattingen gemaakt.

$\mathrm{Bij}$ de doorrekening van netto naar bruto hoeveelheden zaad en meerjarige mosselen is uitgegaan van tarrapercentages van respectievelijk $40 \%$ en $25 \%$. Dit is conform de berekeningen bij bestandsopnamen van wilde mosselbestanden (ref?).

\subsection{Berekeningen}

Uit de monsters die aan het einde van dag $j$ (de dagvangst) verzameld zijn (voor respectievelijk twee grootteklassen ( $i$ ): voor meerjarige mosselen en voor zaad) is op basis van volume een deelmonster 
genomen. De omrekenfactor van dit deelmonster naar het totale dagmonster is uitgerekend door de totale vangst per dag $(V$, liter) te delen door de hoeveelheid deelmonster ( $V d$, liter). Bij deelmonsters met veel (kleine) mosselen is soms slechts een deel van het deelmonsters doorgemeten door het deelmonster in gelijke delen te op te splitsen. In dat geval is de omrekenfactor vermenigvuldigd met het aantal evenredige delen $(x)$ waarin het deelmonster is verdeeld. De omrekenfactor $(f)$ is dus als volgt opgebouwd: $f_{i, j}=V_{i, j} / V d_{i, j} * x_{i, j}$.

Van elk deelmonster uit zowel de dagvangst zaad als uit de dagvangst meerjarige mosselen is het gewicht aan mosselen gemeten en het aantal mosselen geteld. Hierbij is onderscheid gemaakt tussen drie leeftijds- en grootteklassen: zaad (jaarklasse 0), halfwas (meerjarig <45 mm) en consumptiemaat (meerjarig $>45 \mathrm{~mm}$ ). Door het gewicht $(\mathrm{kg})$ aan mosselen in het deelmonster te vermenigvuldigen met de bijbehorend omrekenfactor $(f)$ is de biomassa $(\mathrm{kg})$ van het totale dagmonster uitgerekend. Daarmee is geschat wat er per dag aan biomassa zaadmosselen, halfwasmosselen en consumptiemosselen verzameld is. Deze biomassa's zijn gedeeld door het totale verzamelde volume $(V)$ van die respectievelijke dag. Het resultaat is een schatting van de biomassa aan zaadmosselen, halfwasmosselen en consumptiemosselen per liter monster $(\mathrm{kg} / \mathrm{l})$ voor elke dag dat er bemonsterd is.

Per bemonsteringsstation is de biomassa mosselen per vierkante meter $\left(B, \mathrm{~kg} / \mathrm{m}^{2}\right)$ geschat uit het verzameld volume $(\mathrm{I})$ aan mosselen per bemonsteringsstation, door dit te vermenigvuldigen met respectievelijk de biomassa aan zaadmosselen, halfwasmosselen en consumptiemosselen per liter monster $(\mathrm{kg} / \mathrm{l})$ voor die dag en dit delen door het bemonsterd oppervlak $(A)$ per station (Tabel 2.1).

De netto mosselbiomassa in mosselton ( $\mathrm{mt}=100 \mathrm{~kg}$ ) per gridcel $(k)$, is geschat door de biomassa per vierkante meter $\left(B, \mathrm{~kg} / \mathrm{m}^{2}\right)$ te vermenigvuldigen met de oppervlakte van de bijbehorende grove en fijne gridcel (Tabel 2.1) waarin dit monsterpunt zich bevindt. De netto mosselbiomassa percelen $(\mathrm{mt})$, per grootteklasse is geschat door de mosselbiomassa's van de gridcellen bij elkaar op te tellen.

Tabel 2.1 Parameters oppervlaktebepaling

\begin{tabular}{l|l|l|l}
\hline Parameter & & Eenheid & Waarde \\
\hline$A$ & bemonsterde oppervlakte per station & $\mathrm{m}^{2}$ & 0,276 \\
$g$ & Oppervlakte per gridcel, fijn grid & ha & 8,26 \\
$G$ & Oppervlakte per gridcel, grof grid & ha & 24,78 \\
\hline
\end{tabular}




\section{Resultaten}

De aangetroffen dichtheden van mosselen zijn ruimtelijk weergegeven in Figuur 3.1. Een opsplitsing voor verschillende grootteklassen is bijgevoegd in Bijlage 3. De bijbehorende bestandsgroottes zijn, samen met de resultaten uit voorgaande jaren, samengevat in Tabel 3.1 en in Figuur 3.2.

Het mosselbestand $(B)$ op de percelen in de Waddenzee begin december 2019 is geschat op 89,7 miljoen $\mathrm{kg}$ ( 897.000 mosselton, $1 \mathrm{mt}=100 \mathrm{~kg}$ ) netto versgewicht (in Bijlage 4 is dit uitgesplitst per komberging). Daarvan bestaat 43,3 miljoen kg uit mosselzaad (voornamelijk broedval 2019). Van de 46,4 miljoen $\mathrm{kg}$ meerjarige mosselen bestaat 31,5 miljoen $\mathrm{kg}$ uit halfwas mosselen (schelplengte kleiner dan $45 \mathrm{~mm}$ ) en 14,8 miljoen $\mathrm{kg}$ uit consumptie mosselen (schelplengte van minstens $45 \mathrm{~mm}$ ). Uitgaande van tarrapercentages van $40 \%$ en $25 \%$ voor respectievelijk mosselzaad en meerjarige mosselen komt de bruto mosselbiomassa op de percelen uit op 134,0 miljoen $\mathrm{kg}$ (1.340.000 mt) versgewicht, waarvan 72,2 miljoen $\mathrm{kg}$ mosselzaad en 61,8 miljoen $\mathrm{kg}$ meerjarige mosselen. Het areaal van kweekpercelen met mosselen in de Waddenzee wordt geschat op 2651 ha ten tijde van de bemonstering.

Tabel 3.1. Het mosselbestand op mosselkweekpercelen in de Waddenzee vanaf 2004. Bij de omrekening van netto naar bruto hoeveelheden is voor mosselzaad en meerjarige mosselen uitgegaan van een tarrapercentage van resp. 40\% en 25\%. 1 Mosselton $(\mathrm{mt})=100 \mathrm{~kg}$. De gegevens tot en met 2011 zijn afkomstig uit (De Mesel and Wijsman 2011) en (Wijsman and Jol 2012). Het te borgen bestand (uit Van Stralen, 2019) is de minimale hoeveelheid mosselen die de betreffende winter op de percelen aanwezig moet zijn en mag niet meer zijn dan het gemeten bestand.

\begin{tabular}{|c|c|c|c|c|c|c|c|c|c|}
\hline \multirow{2}{*}{$\begin{array}{l}\text { Mosselbestand } \\
\text { kweekpercelen } \\
\text { Waddenzee }\end{array}$} & \multicolumn{5}{|c|}{ Netto bestand (miljoen kg) } & \multicolumn{4}{|c|}{ Bruto bestand (mt x 1000) } \\
\hline & Zaad & $\begin{array}{l}\text { Halfwas } \\
(<45 \mathrm{~mm})\end{array}$ & $\begin{array}{c}\text { Groot } \\
(\geq 45 \mathrm{~mm})\end{array}$ & $\begin{array}{r}\text { Tot } \\
\text { Gemeten } \\
\text { bestand } \\
\end{array}$ & \begin{tabular}{l|}
$\mathbf{I}$ \\
borgen \\
estand
\end{tabular} & Zaad & $\begin{array}{l}\text { Halfwas } \\
(<45 \mathrm{~mm})\end{array}$ & $\begin{array}{c}\text { Groot } \\
(\geq 45 \mathrm{~mm})\end{array}$ & Totaal \\
\hline $2004-$ dec & 1,0 & 15,2 & 31,9 & 48,1 & & 17 & 203 & 425 & 644 \\
\hline 2005- dec & 8,9 & 0,9 & 5,2 & 14,9 & 1,3 & 148 & 12 & 69 & 228 \\
\hline 2006- dec & 1,0 & 5,8 & 29,0 & 35,8 & 5,0 & 17 & 77 & 387 & 481 \\
\hline 2007- dec & 17,5 & 2,5 & 15,3 & 35,3 & 3,0 & 291 & 33 & 204 & 528 \\
\hline 2008- dec & 11,8 & 2,1 & 15,8 & 29,7 & 12,4 & 196 & 28 & 211 & 435 \\
\hline 2009- dec & 15,4 & 2,8 & 28,3 & 46,5 & 17,1 & 257 & 38 & 377 & 672 \\
\hline 2010- dec & 7,6 & 11,0 & 28,9 & 47,5 & 18,9 & 127 & 147 & 385 & 659 \\
\hline $2011-$ dec & 8,9 & 1,3 & 11,8 & 21,9 & 8,7 & 148 & 17 & 157 & 322 \\
\hline 2013 - jan & 39,6 & 1,5 & 5,6 & 46,7 & 9,7 & 660 & 20 & 74 & 754 \\
\hline 2013 - april & 52,5 & 1,7 & 4,7 & 58,9 & & 875 & 23 & 62 & 960 \\
\hline $2013-$ dec & 14,3 & 31,1 & 4,7 & 50,1 & 28,2 & 238 & 415 & 63 & 716 \\
\hline 2014 - juli & 7,5 & 33,3 & 20,3 & 61,1 & & 124 & 444 & 271 & 840 \\
\hline 2014 - dec & 37,7 & 7,6 & 13,4 & 58,7 & 13,6 & 629 & 101 & 179 & 909 \\
\hline 2015 - juni & 40,7 & 11,7 & 13,5 & 65,8 & & 678 & 155 & 180 & 1013 \\
\hline 2015 - dec & 45,6 & 9,5 & 12,4 & 67,5 & 9,3 & 761 & 126 & 165 & 1052 \\
\hline 2016 - juni & 62,6 & 21,3 & 15,2 & 99,1 & & 1044 & 284 & 202 & 1530 \\
\hline 2017 - feb & 48,1 & 14,6 & 9,1 & 71,8 & 21,3 & 802 & 195 & 121 & 1118 \\
\hline 2017 - juli & 80,3 & 20,4 & 18,0 & 118,8 & & 1339 & 272 & 240 & 1851 \\
\hline $2018-$ feb & 20,8 & 20,2 & 9,3 & 50,4 & 48,0 & 346 & 270 & 394 & 741 \\
\hline 2018 - juni & 25,0 & 22,3 & 23,7 & 71,0 & & 416 & 297 & 316 & 1030 \\
\hline $2018-\mathrm{dec}$ & 52,9 & 11,3 & 27,3 & 91,5 & 16,7 & 882 & 151 & 364 & 1396 \\
\hline 2019 - juli & 57,8 & 18,3 & 17,9 & 94,1 & & 964 & 245 & 239 & 1448 \\
\hline $2019-$ dec & 43,3 & 31,5 & 14,8 & 89,7 & 31,8 & 722 & 420 & 198 & 1340 \\
\hline gem. winter '04-'19 & 23,4 & 10,6 & 16,4 & 50,4 & & 390 & 141 & 219 & 750 \\
\hline
\end{tabular}




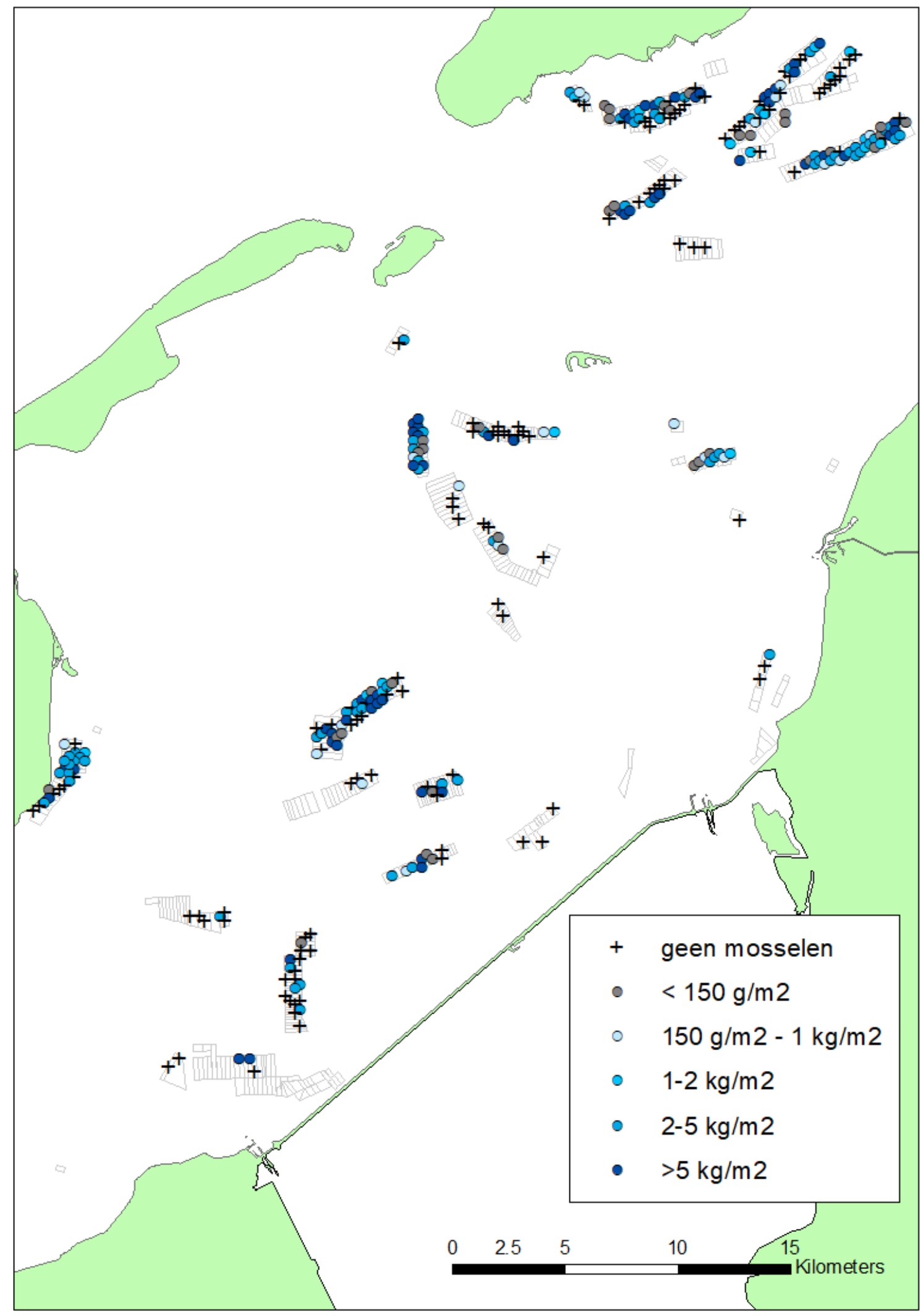


Figuur 3.1 Dichtheid van mosselen op mosselkweekpercelen in de Waddenzee in december 2019 in gram versgewicht per $m^{2}$.

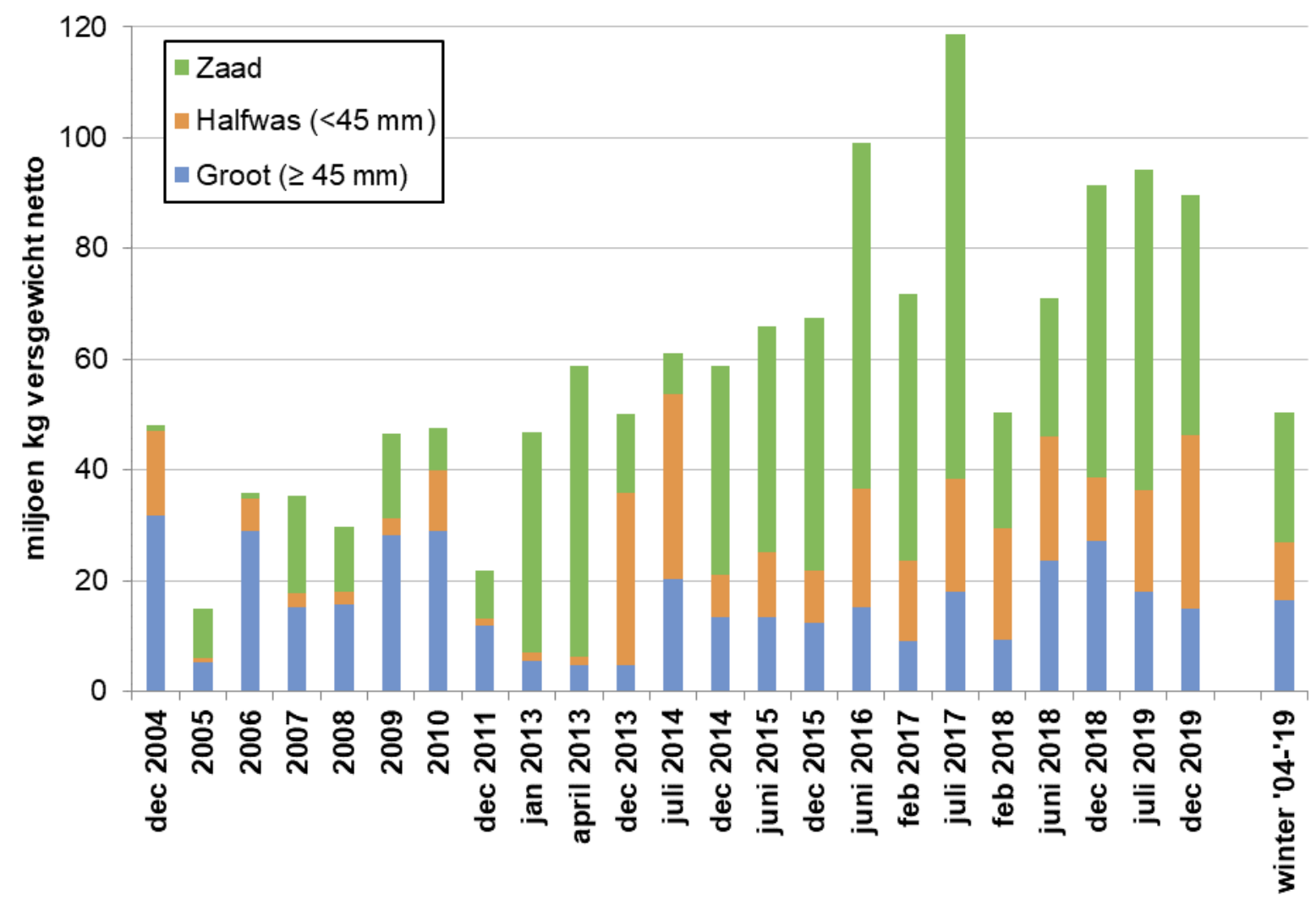

Figuur 3.2 Mosselbestand in miljoen $\mathrm{kg}$ netto versgewicht op mosselkweekpercelen in de Waddenzee in de periode december 2004 - december 2019 met meest rechts de gemiddelde biomassa in de winters van 2004 - 2019. De mosselen zijn onderverdeeld in mosselzaad en meerjarige mosselen groter en kleiner dan $45 \mathrm{~mm}$. De onderliggende gegevens zijn opgenomen in Tabel 3.1.

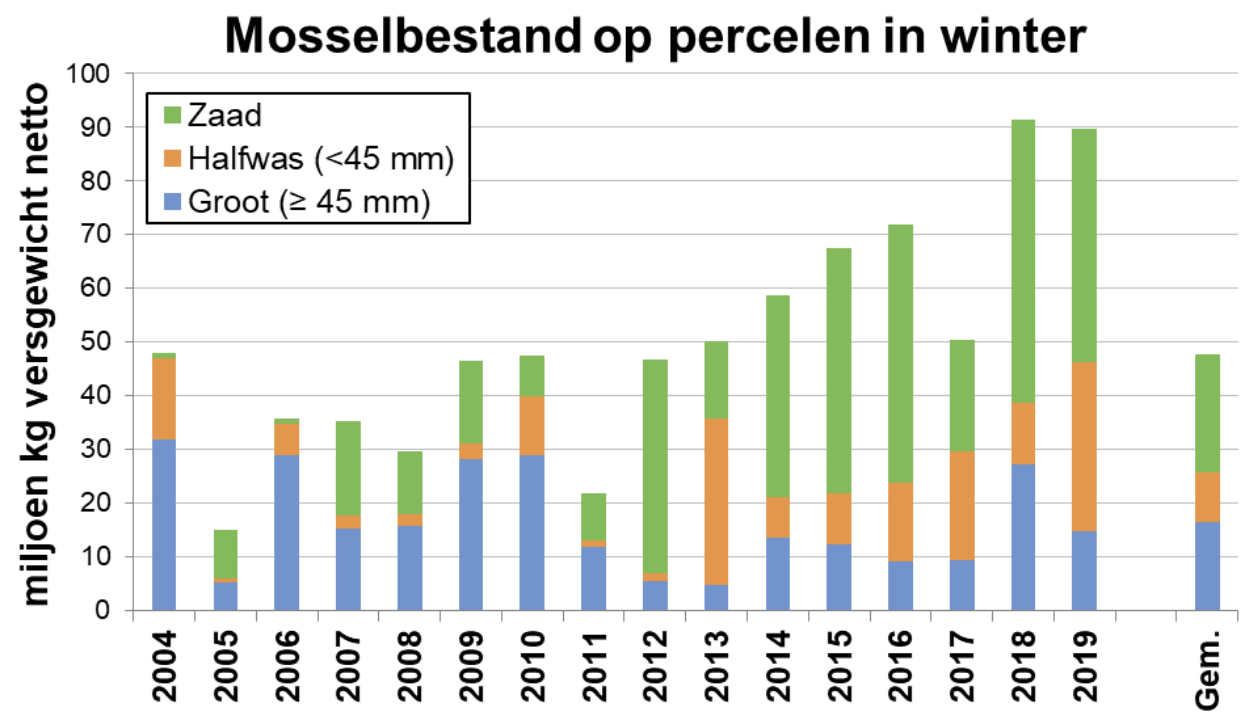

Figuur 3.3 Subset van Figuur 3.2: Mosselbestand in miljoen $\mathrm{kg}$ netto versgewicht op mosselkweekpercelen in de Waddenzee in de winter vanaf 2004. De mosselen zijn onderverdeeld in mosselzaad en meerjarige mosselen groter en kleiner dan $45 \mathrm{~mm}$. 


\section{$4 \quad$ Conclusie}

In december 2019 is met een geïnventariseerd bestand van 89,7 miljoen kg versgewicht voor het tweede opeenvolgende jaar een relatief hoog winterbestand mosselen op de percelen gevonden. Hier draagt vooral een relatief hoog bestand aan mosselzaad (43.3 $\mathrm{Mkg}$ ) aan bij. Het overgrote deel van het bestand aan meerjarige mosselen op de percelen bestond uit halfwas mosselen ( $31.5 \mathrm{Mkg})$, met een relatief laag bestand (minder dan gemiddeld) aan mosselen van consumptiemaat (14.8 Mkg).

Als onderdeel van de vergunningverlening voor de mosselzaadvisserij in het voorjaar van 2019 is berekend dat in het najaar van 2019 een bestand van minimaal 31,8 miljoen kg netto aanwezig diende te zijn (van Stralen 2019). Die hoeveelheid was dus ruimschoots aanwezig op de peildatum van 1 december 2019. 


\section{$5 \quad$ Literatuur}

Capelle, J. J., en M. R. van Stralen. 2019. Bestandsopname van mosselen op mosselkweekpercelen in de Waddenzee in december 2018. Wageningen Marine Research, Yerseke.

De Mesel, I., and J. W. M. Wijsman. 2011. Bestandsschatting mosselen op percelen in de Oosterschelde (1992-2009) en de Waddenzee (2004-2009). C076/11, Yerseke.

LNV. 2018. Bijlage 1; overwegingen; meerjarige vergunning; vooren najaarsmosselzaadvisserijen 20182020. Kenmerk DGAN-NB/18. Den Haag.

Van Stralen, M. R. 2013. Bestandsopname van mosselen op mosselkweekpercelen in de Waddenzee in de winter van 2012-2013. Marinx.

van Stralen, M. R. 2018. Passende Beoordeling van de mosselvisserij in het sublitoraal van de Westelijke Waddenzee in de periode 2018-2020. Marinx, Scharendijke.

van Stralen, M. R. 2019. Bijlage bij het Visplan mosselzaadvisserij voorjaar 2019; Doorrekening VKA model voorjaar 2019. Marinx, Scharendijke.

Wijsman, J. W. M., and J. Jol. 2012. Onderzoeksproject Duurzame Schelpdiervisserij (PRODUS). Deelproject 1A. Bepaling bestand op de mosselpercelen in de Waddenzee najaar 2011 (Mussel stock assessment on culture plots in the Waddensea in autumn 2012, report in Dutch). C022/08, Wageningen IMARES, Yerseke. 


\section{Verantwoording}

Rapport C017/20

Projectnummer: 4313200007-07

Dit rapport is met grote zorgvuldigheid tot stand gekomen. De wetenschappelijke kwaliteit is intern getoetst door een collega-onderzoeker en het verantwoordelijk lid van het managementteam van Wageningen Marine Research

Akkoord: $\quad$ Dr.ir. H.M. Jansen

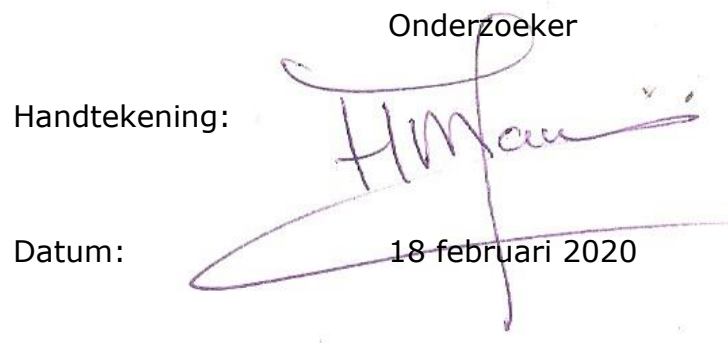

Akkoord: Drs. J. Asjes

Manager integratie

Handtekening:

Datum:

18 februari 2020 


\section{Bijlage 1 Monstergrid}
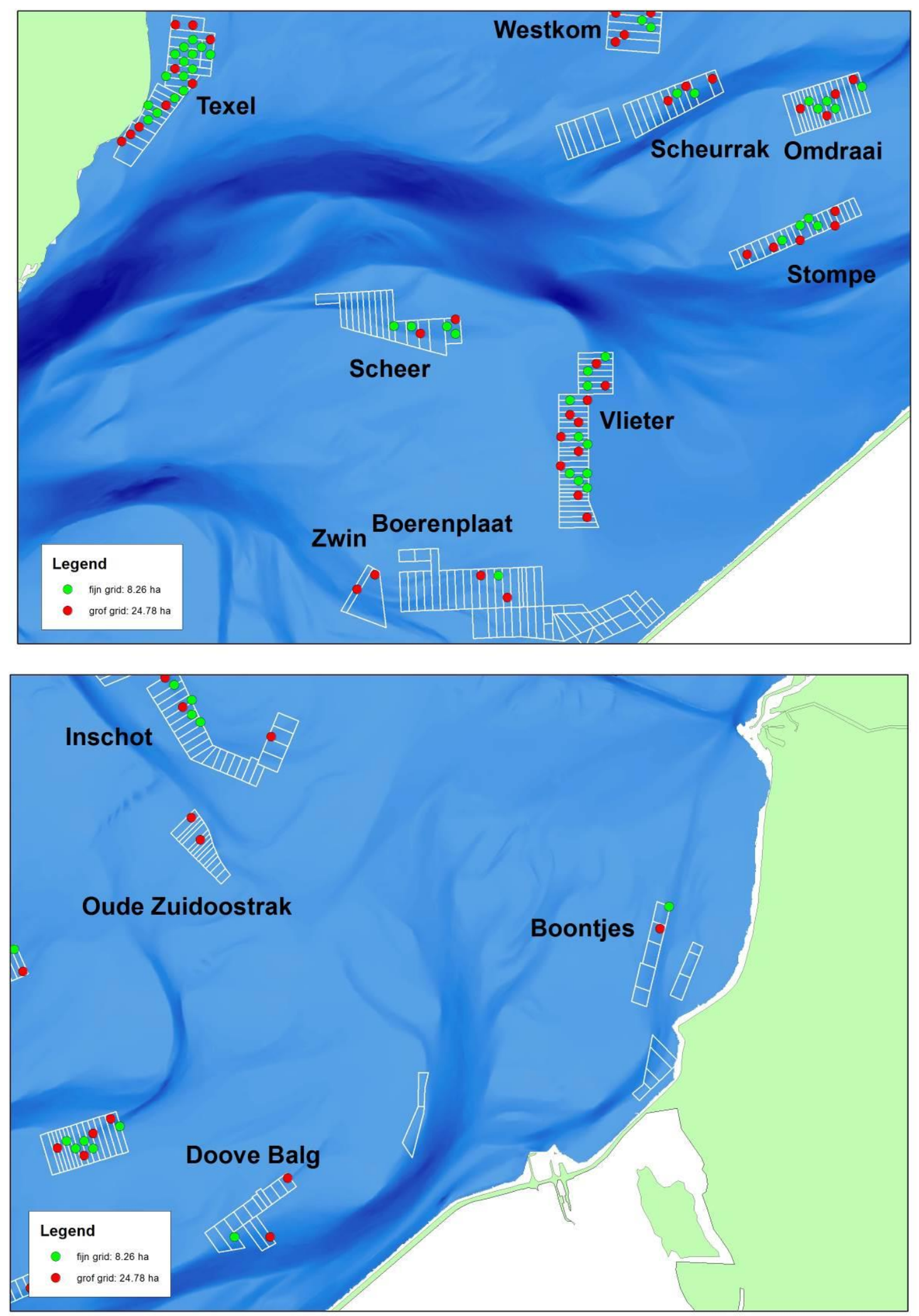

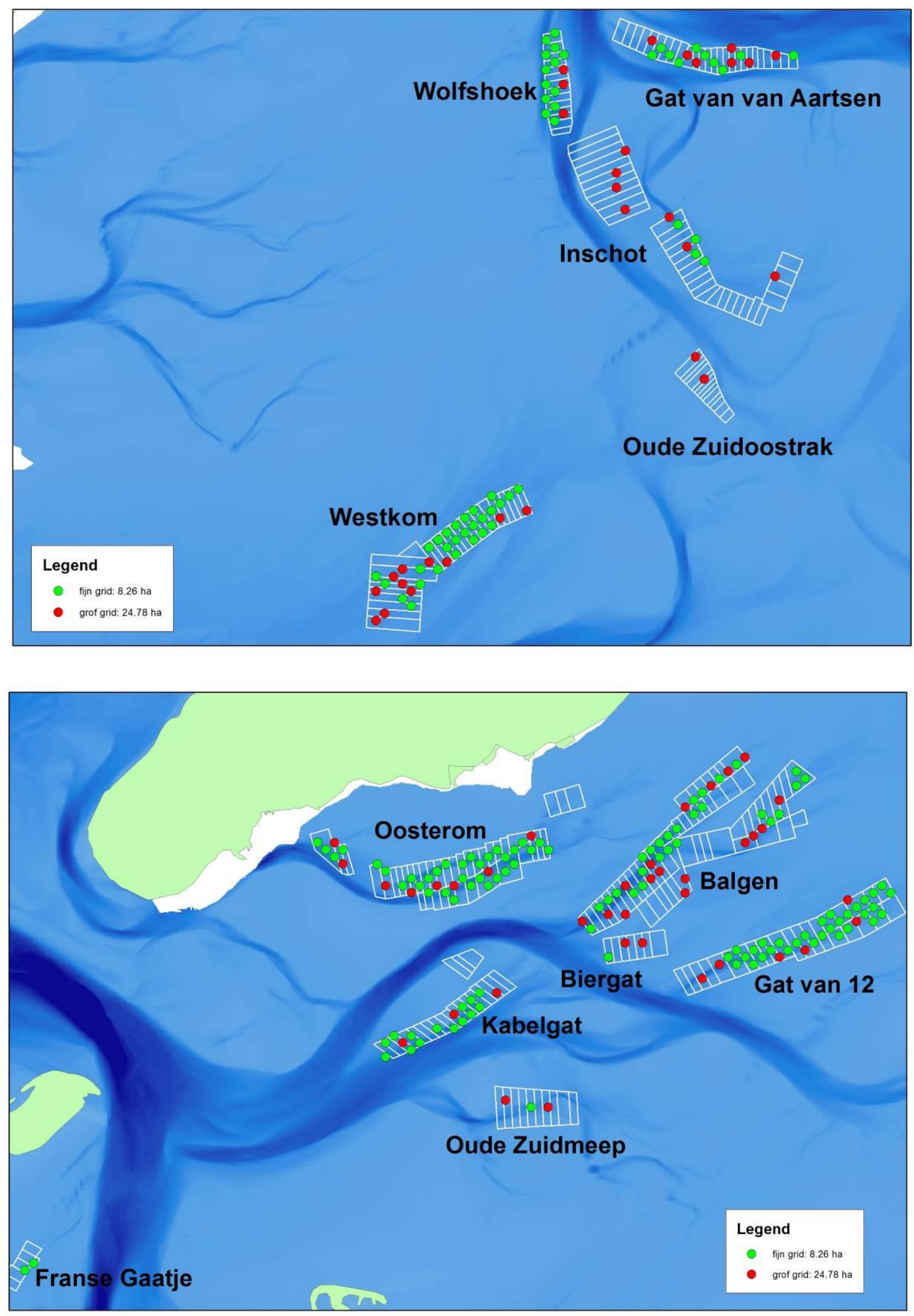


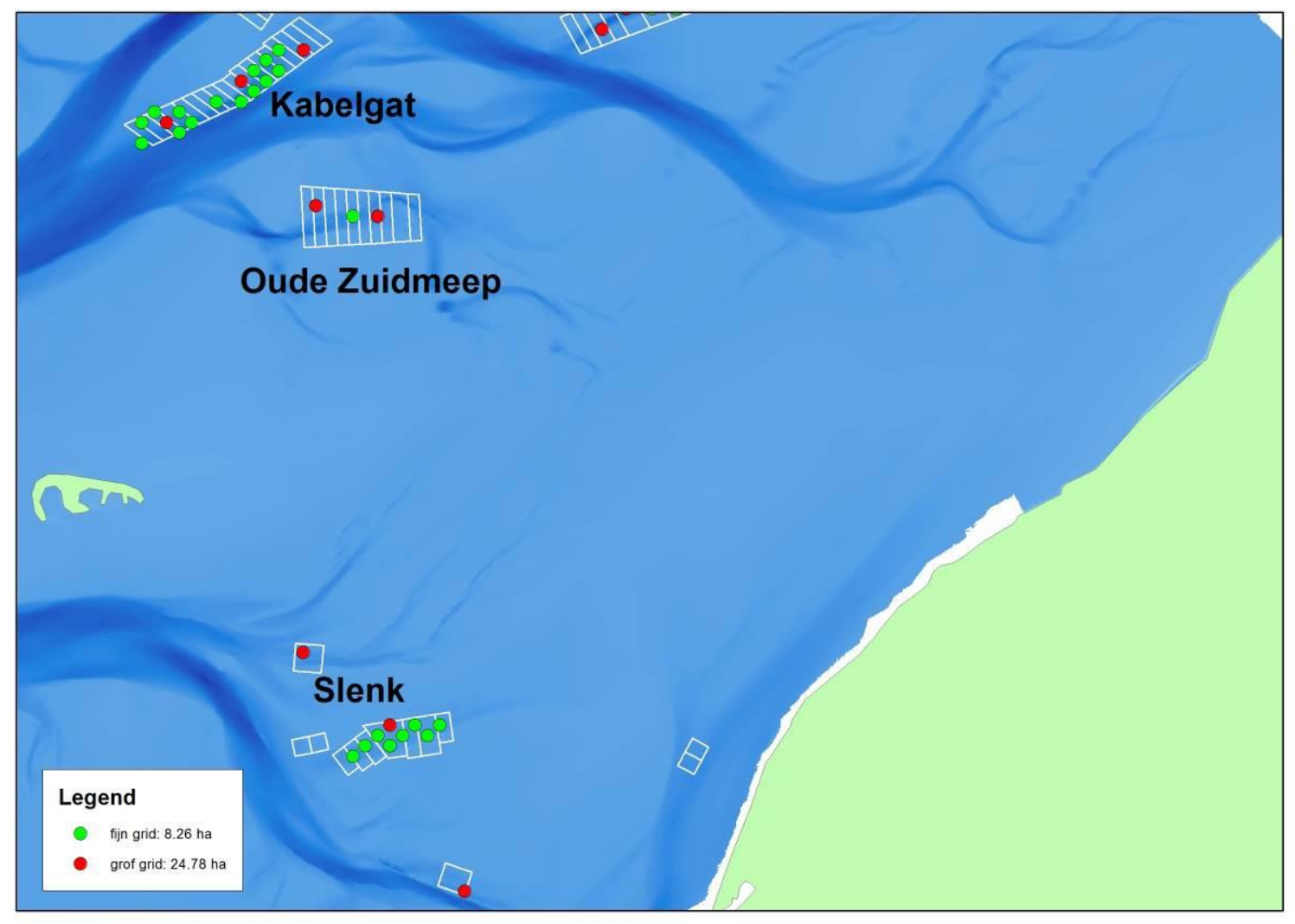




\section{Bijlage 2 Protocol monstername}

\section{Handleiding bemonstering mosselpercelen}

versie 7 november 2014

\section{Monstername per station}

- Op elk station $\mathbf{5}$ happen

- Bij elkaar in een mand, spoelen

- Zeesterren uit de vangst halen, aantal noteren en bewaren in verzamel-emmer

- Idem voor krabben met schild groter dan $2 \mathrm{~cm}$ (duimnagel)

- Volume van de vangst bepalen in bekerglas. Aflezen in tienden liters. Wanneer het maar een paar mosselen zijn ("bewijsje") een "B" invullen. Wanneer er geen mosselen in de vangst zitten kan tarra over boord en is de vangst "nul".

- Bewaren in verzamelmand Zaad c.q. Halfwas + Cons. Bij mengsel indelen op dominante soort

- Aan dek: sample nummers ("treknummers" van die dag) invullen

- Brug: trek nummers noteren op de kaartjes.

\section{Invullen meetliist aan dek}

De blauwe waarden moeten worden ingevuld, hier als voorbeeld

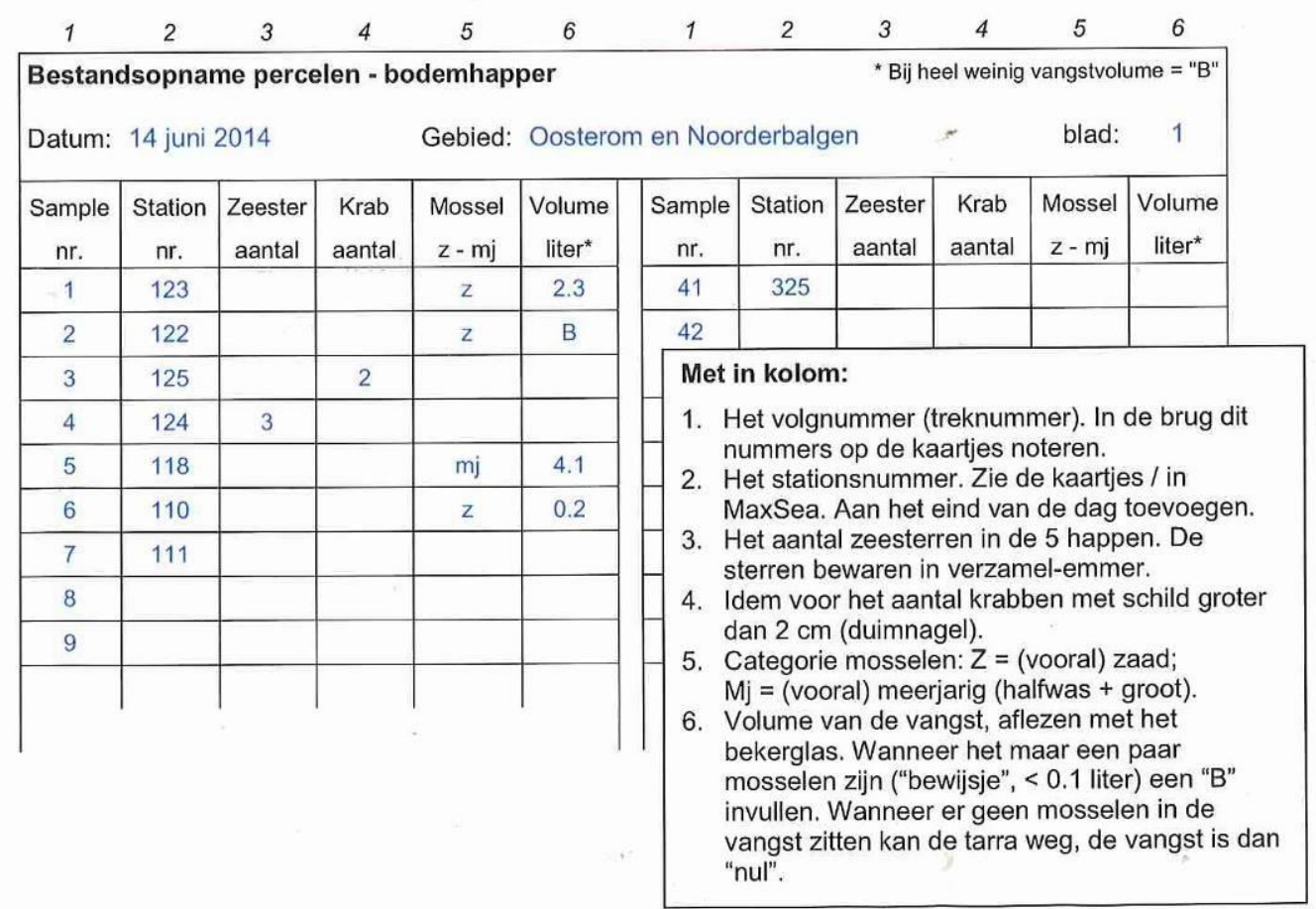




\section{Verwerken vangst per dag}

Uit de verzamelmanden wordt per dag een monster genomen en uitgezocht:

\section{Bepalen vangstvolume en het nemen van een subsample}

Van beide verzamelmanden vangstvolume bepalen in liters: grote zwarte emmer $=20$ liter, kleine zwarte emmer $=12$ liter of met maatbeker.

Volumes emmers graag nog even checken: Door de emmers met bekerglas te vullen met water.

- Vangst mengen en neem subsample op volume:

$>$ Zaad 3.5 liter $=1$ doorzichtig emmertje, uit "zaad" verzamel-mand

$>$ Meerjarig 6 liter $=$ wit emmertje, uit de andere mand

- Wanneer de vangst kleiner is dan 3.5 resp. 6 liter, dan de hele vangst als monster nemen.

\section{Uitzoeken subsamples}

Zie ook het voorbeeld zoals ingevulde tabel op volgende pagina

- Beide monsters liefst helemaal uitzoeken

- Uitzoeken op zaad, halfwas (= meerjarig en $<45 \mathrm{~mm}$ ) en groot (= meerj. en $>45 \mathrm{~mm}$ )

- Ontpokken

- Mosselen tellen en wegen, de kapotte mosselen alleen tellen

- Pokken wegen

- Zeesterren en krabben: tellen en wegen

- Bij later wegen de mosselen, krabben en zeesterren bewaren in water in verband met vochtverlies. 


\section{Bijlage 3 Kaarten mosseldichtheid per grootteklasse.}

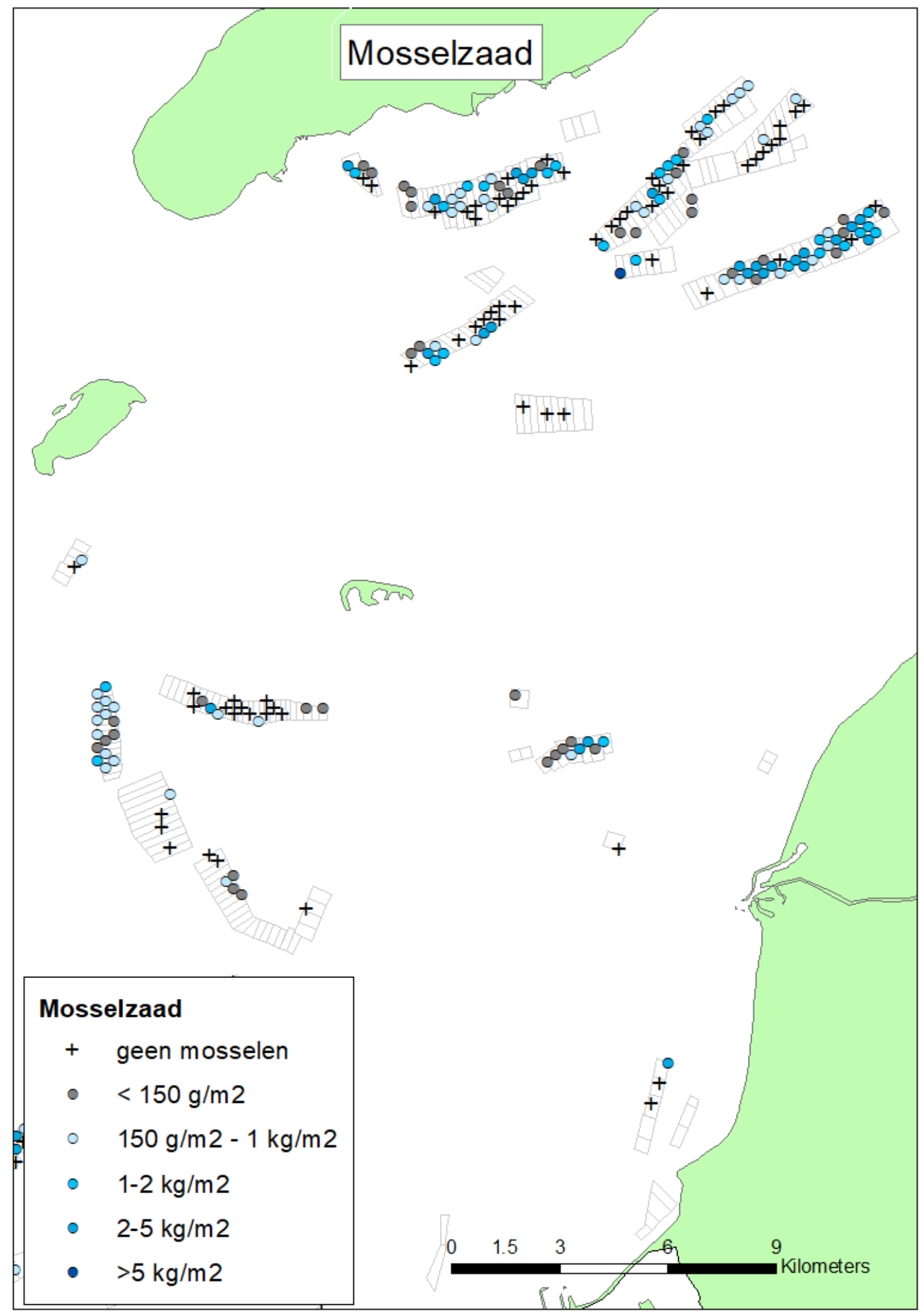




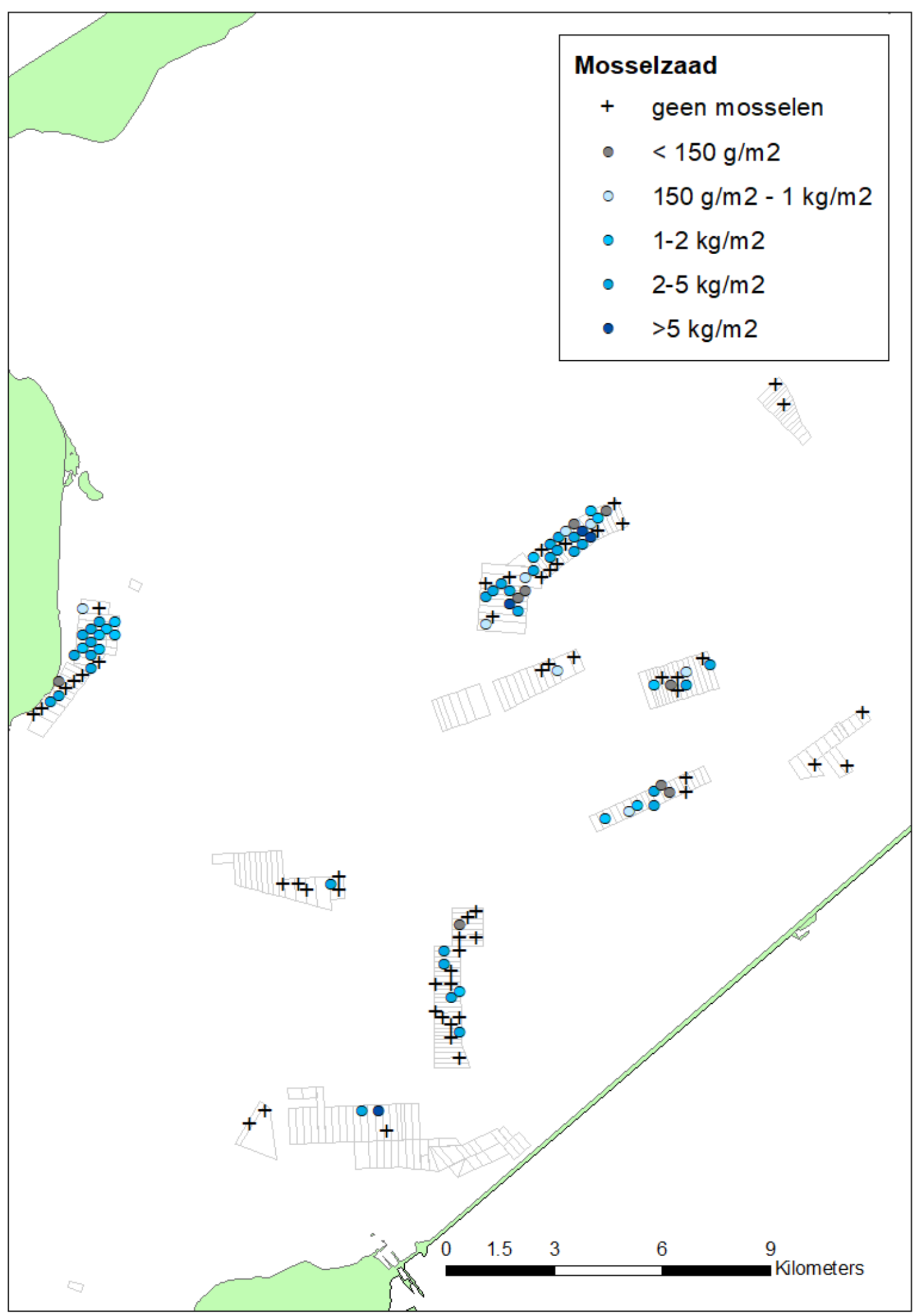




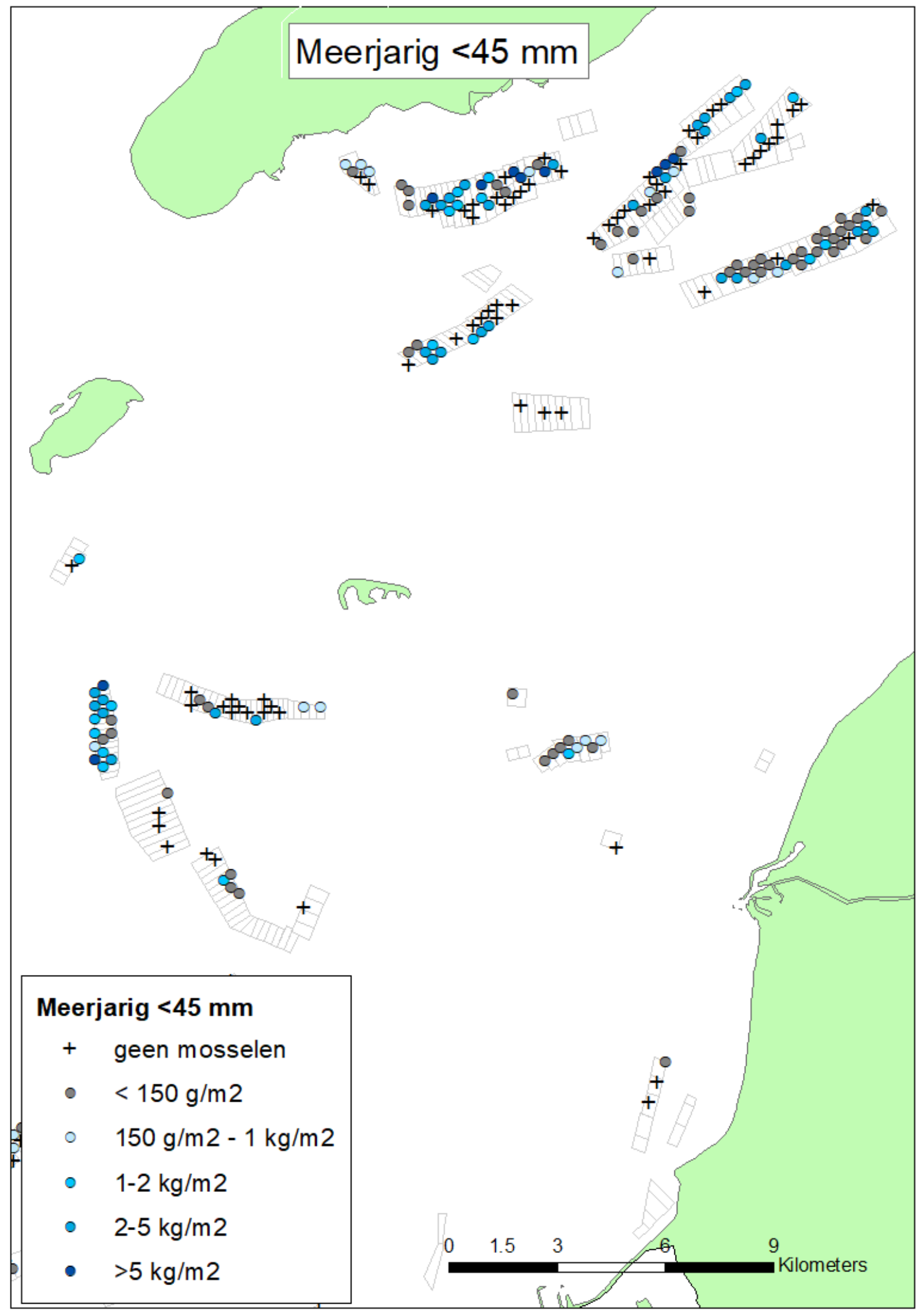




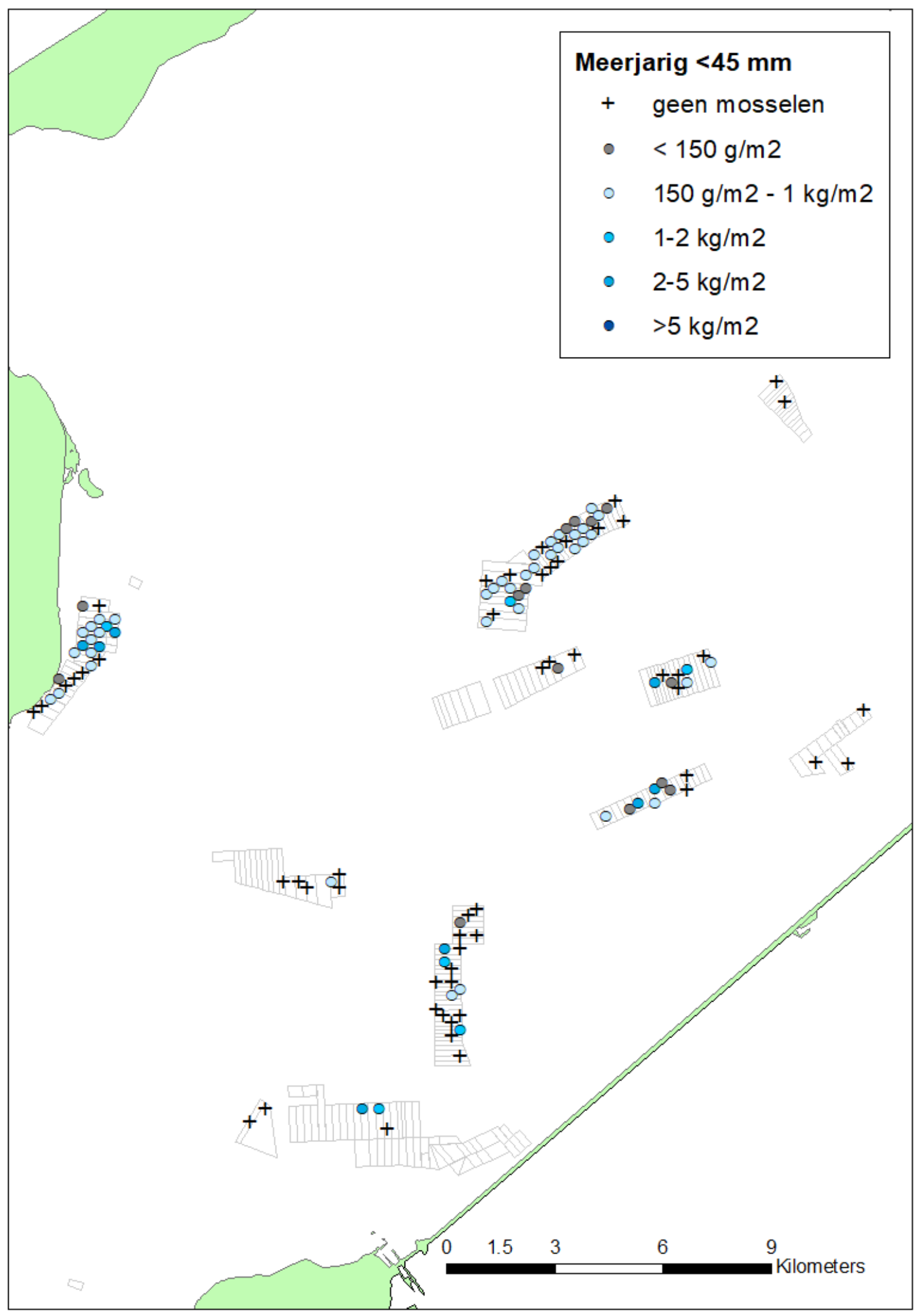




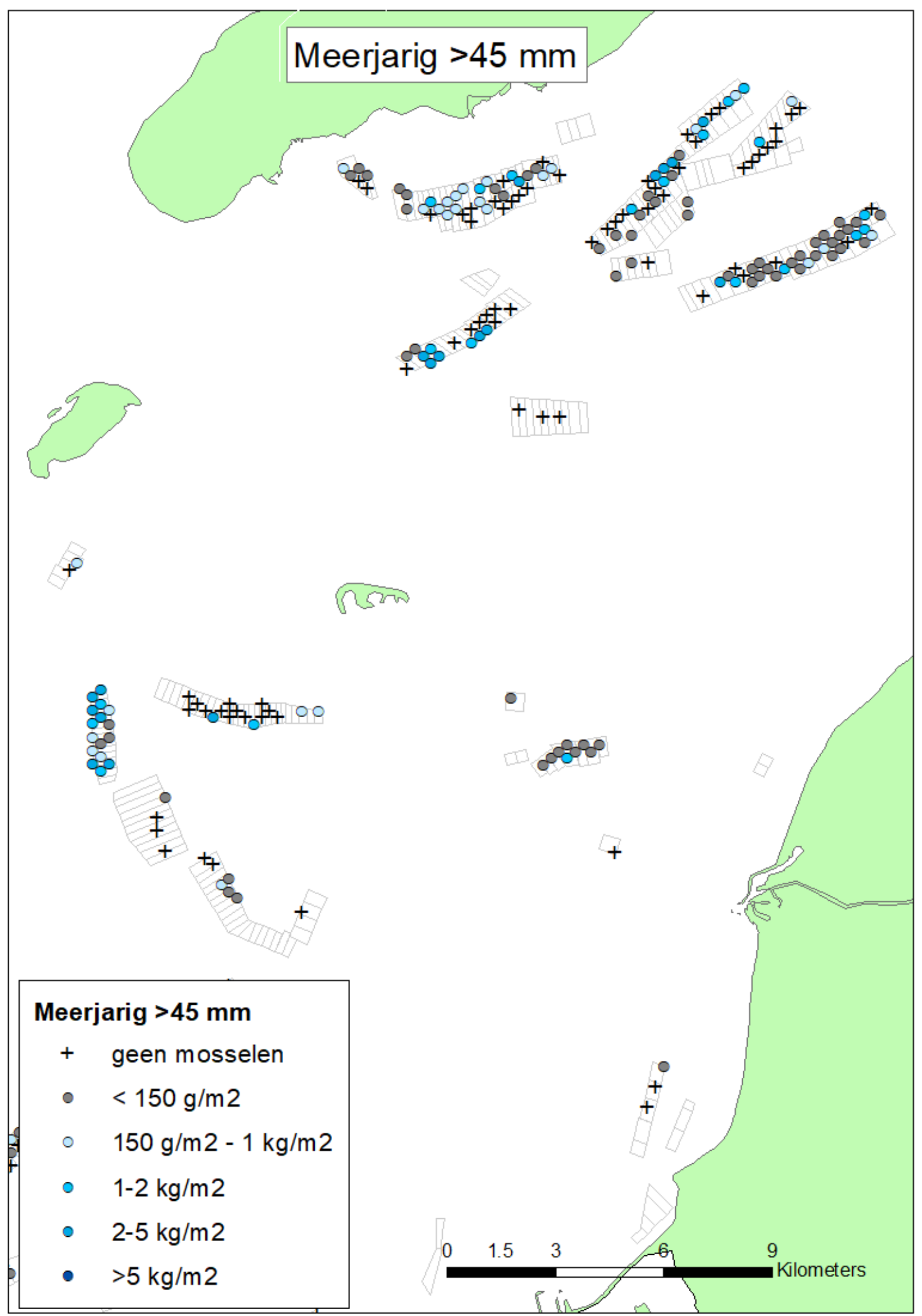




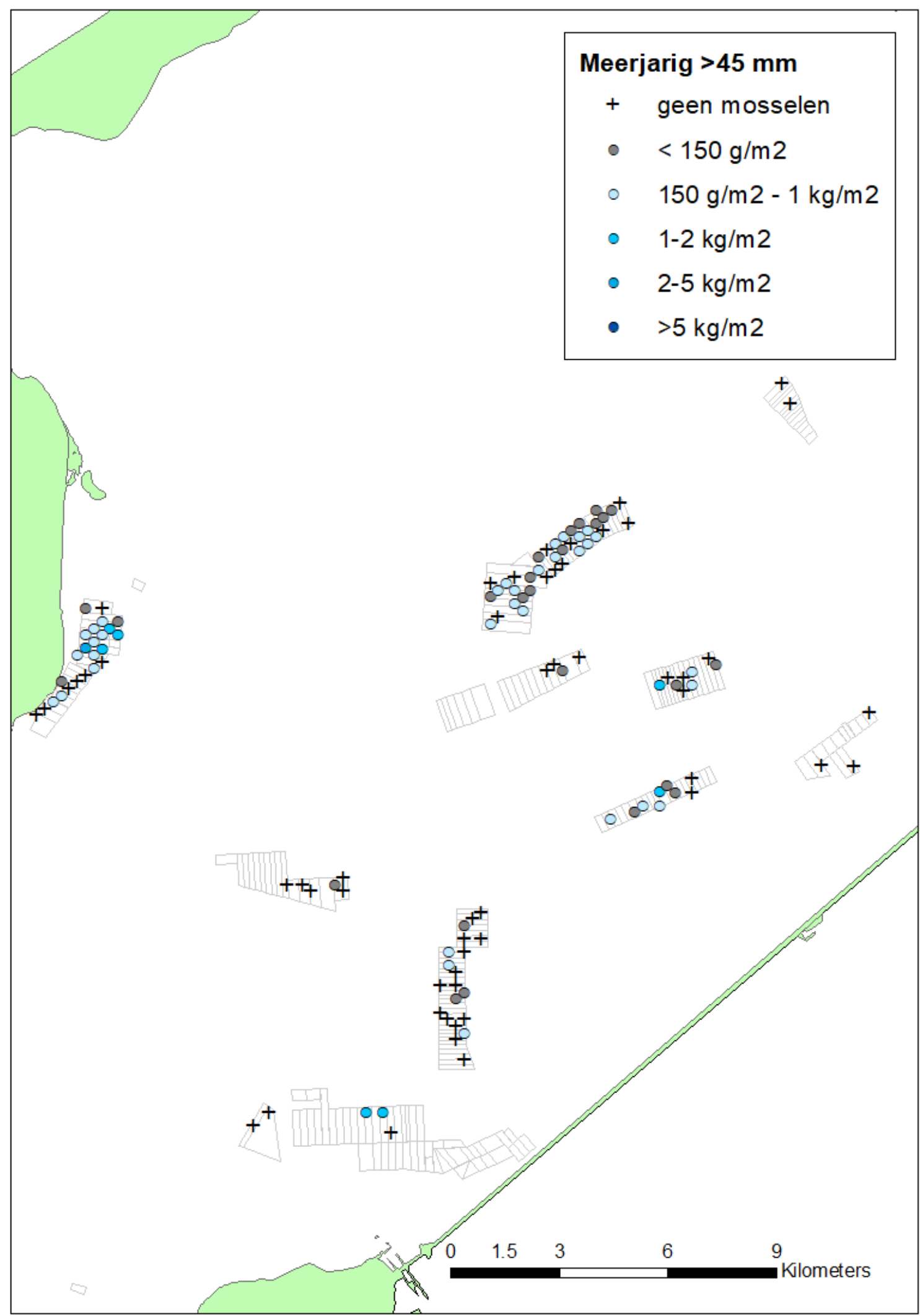




\section{Bijlage 4 Bestand per kombergingsgebied}

\begin{tabular}{l|llll}
\hline \multirow{2}{*}{ Komberging } & \multicolumn{2}{l}{ Netto bestand, miljoen kg } & & \\
& Zaad & $\begin{array}{l}\text { Halfwas } \\
(<45 \mathrm{~mm})\end{array}$ & $\begin{array}{l}\text { Groot } \\
(>45 \mathrm{~mm})\end{array}$ & Totaal \\
\hline Marsdiep (Phoca + boontjes) & $27,4(70 \%)$ & $78,1(20 \%)$ & $38,3(10 \%)$ & $39,1(100 \%)$ \\
Vlie (Asterias excl. boontjes) & $15,9(31 \%)$ & $23,7(47 \%)$ & $11,0(22 \%)$ & $50,7(100 \%)$ \\
\hline
\end{tabular}


Wageningen Marine Research

T: +31 (0)317480900

E: marine-research@wur.nl

www.wur.nl/marine-research

Bezoekers adres:

- Ankerpark 271781 AG Den Helder

- Korringaweg 7, 4401 NT Yerseke

- Haringkade 1, 1976 CP IJmuiden
Wageningen Marine Research levert met kennis, onafhankelijk wetenschappelijk onderzoek en advies een wezenlijke bijdrage aan een duurzamer, zorgvuldiger beheer, gebruik en bescherming van de natuurlijke rijkdommen in zee-, kust- en zoetwatergebieden.

Wageningen Marine Research is onderdeel van Wageningen University \& Research. Wageningen University \& Research is het samenwerkingsverband tussen Wageningen University en Stichting Wageningen Research en heeft als missie: 'To explore the potential of nature to improve the quality of life' 